УДК 665.644.44

ИССЛЕДОВАНИЕ ПРОЦЕССА АРОМАТИЗАЦИИ СЫРЬЯ РИФОРМИНГА НА ЦЕОЛИТСОДЕРЖАЩЕМ КАТАЛИЗАТОРЕ

\title{
RESEARCH OF THE RAW MATERIAL AROMATIZATION \\ REFORMING PROCESS ON THE ZEOLITE-CONTAINING \\ CATALYST
}

Муниров Т.А., Давлетшин А.Р., Ахметов А.Ф., Шириязданов Р. Р., Хамзин Ю.А., Ганцев А.В., Амангельдиев Д.М.

Уфимский государственный нефтяной технический университет, г. Уфа, Российская Федерация

T.A. Munirov, A.R. Davletshin, A.F. Akhmetov, R.R. Shiriyazdanov, Yu.A. Khamzin, A.V. Gantsev, D.M. Amangeldiyev

Ufa State Petroleum Technological University, Ufa, Russian Federation

e-mail: fueldep@inhp.ru, e-mail: petroleum9@bk.ru

Аннотация. Более 50 \% суммарного бензинового фонда России приходится на риформаты, что делает каталитический риформинг важнейшим процессом отечественной нефтепереработки. В связи с этим значительное количество работ за последние годы посвящено модернизации процесса риформинга.

Несмотря на то, что традиционно для ароматизации сырья применяются платиносодержащие катализаторы, перспективное направление имеют поиск и разработка более дешевых бесплатиновых катализаторов, предъявляющих менее жесткие требования к качеству сырья. 
Ранее проведены исследования процесса риформинга на неплатиновых катализаторах в безводородном режиме для усиления целевых реакций. Приведены результаты проведенных исследований, на основе которых был подобран цеолитсодержащий катализатор для использования на одной из стадий риформирования сырья. На основе представленных данных по изменению содержания нафтенов в продуктах по сравнению с сырьем сделан вывод о механизме реакций, протекающих на выбранном катализаторе.

В настоящей работе приведены результаты исследования процесса каталитического риформинга на цеолитсодержащем катализаторе в присутствие водорода. Осуществлен литературный обзор последних тенденций развития процесса каталитического риформинга. В качестве сырья использована прямогонная гидроочищенная бензиновая фракция 85-180 ${ }^{\circ} \mathrm{C}$. Опыты проведены при температурах $300{ }^{\circ} \mathrm{C}, 350{ }^{\circ} \mathrm{C}$ и $400{ }^{\circ} \mathrm{C}$ и объемных скоростях подачи сырья 1, 2, 3 и 4 ч$^{-1}$ с целью подбора оптимальных параметров. Представлены результаты экспериментов, приведено обсуждение углеводородного состава продуктов при каждой температуре процесса. На основе полученных результатов сделан вывод о целесообразности применения цеолитсодержащего катализатора на стадии предварительной ароматизации сырья риформинга.

Abstract. More than $50 \%$ of the total gasoline fund of Russia falls on the reformates, which makes catalytic reforming the most important process of domestic oil refining. In this regard, a significant amount of work in recent years is devoted to the modernization of the reforming process.

Despite the fact that platinum-containing catalysts are traditionally used in the process of raw materials aromatization, the search for and development of cheaper platinum-free catalysts with less stringent requirements to the quality of raw materials is a promising direction.

Earlier research of the reforming process on non-platinum catalysts in nonhydrogen regime to enhance the target reactions have been conducted. In the 
scientific article the results are given, on the basis of which the zeolitecontaining catalyst was selected for use in one of the stages of catalytic reforming. On the basis of the provided data about change in the content of naphthenes in products compared with raw materials, a conclusion is drawn about the mechanism of reaction proceeding on this catalyst.

In the scientific articles the results of a study of the catalytic reforming process on a zeolite-containing catalyst in the presence of hydrogen are presented. A literature review of the latest trends in the development of the catalytic reforming process is carried out. A straight-run hydrotreated gasoline fraction of $85-180^{\circ} \mathrm{C}$ was used as a raw material. Experiments were carried out at temperatures of $300{ }^{\circ} \mathrm{C}, 350{ }^{\circ} \mathrm{C}$ and $400{ }^{\circ} \mathrm{C}$ and volumetric feed rates of 1,2 , 3 , and $4 \mathrm{~h}^{-1}$ for the purpose of selecting optimal parameters. The results of experiments are presented, the hydrocarbon composition of the products is discussed at each process temperature. Based on the obtained results, it was concluded that the use of the zeolite-containing catalyst in the preliminary aromatization of the reforming feedstock is advisable.

Ключевые слова: каталитический риформинг, ароматические углеводороды, цеолитсодержащий катализатор, ароматизация, коксообразование, бензин.

Key words; catalytic reforming, aromatic hydrocarbons, zeolite-containing catalyst, aromatization, coke formation, gasoline.

С ростом мощностей переработки нефти и повышением спроса на моторное топливо в последние годы особое внимание уделяется вопросу дальнейшего развития процесса каталитического риформинга как одного из основных поставщиков компонента для производства товарных автобензинов в РФ.

Помимо увеличения количества вырабатываемых высокооктановых компонентов автобензина, важным фактором является соответствие 
качества получаемых моторных топлив экологическим стандартам Евро-5 [1]. В связи с этим проводится большое количество исследований в области разработки комбинированных процессов риформирования, изомеризации и ректификации. Разделение продуктов на промежуточных ступенях риформинга с целью дальнейшего проведения гидроизомеризации позволяет повысить технико-экономические показатели процесса. Различные варианты технологии комбинированных установок описаны в работах [2-4].

Важным фактором при оценке эффективности работы установки являются эксплуатационные характеристики катализатора. Основными параметрами при выборе катализатора являются селективность и продолжительность рабочего цикла. На большинстве НПЗ России применяется продукция зарубежных производителей (UOP, Axens, Criterion). Доля загрузки отечественными катализаторами составляет порядка 30 \% [5]. Несмотря на разнообразие марок, представленных на рынке, составы каталитических систем схожи. Как правило, в качестве активного компонента, применяются платина (содержание 0,25-0,35 \% масс.) и рений $(0,25-0,40 \%$ масс.) [6]. Опыт эксплуатации отечественных и зарубежных катализаторов риформинга, описанный в работе [6], показывает, что эффективность работы катализаторов российских производителей не уступает импортным аналогам.

Независимо от фирмы производителя, платиносодержащие катализаторы имеют ряд недостатков: высокая стоимость, подверженность воздействию каталитических ядов, снижение активности в результате накопления кокса на поверхности. Так, важным фактором эффективной эксплуатации катализатора является минимизация реакции коксообразования.

В работах [7-10] были изучены механизмы и динамика отложения коксогенных структур на активных центрах катализатора. Известно, что на поверхности катализатора возможно образование обратимого кокса с 
высоким содержанием водорода и необратимого (графитного), который связан с металлом и беден водородом [10]. Удаление графитного кокса невозможно в условиях промышленной регенерации ввиду наличия структур с температурой выгорания выше $800{ }^{\circ} \mathrm{C}$. Образование подобных соединений связано с нарушением равновесия реакций гидрирования и образования промежуточных продуктов уплотнения. Минимизация подобных негативных эффектов возможна за счет непрерывного мониторинга технологического режима и своевременной корректировки параметров процесса. Поддержание активности катализатора в оптимальных пределах стало возможно благодаря методам математического моделирования, описанным в работах [9-12].

Неравномерность дезактивации катализатора по слоям также ведет к образованию графитного кокса вследствие несовершенства работы распределительных устройств подачи сырья в промышленных реакторах. Снижение неравномерности движения потока возможно при изменении направления газосырьевой смеси от центра реактора к периферии [13-15]. Помимо увеличения рабочего ресурса катализатора, подобная модернизация внутреннего устройства аппарата позволяет улучшить общие технико-экономические показатели процесса риформинга [13].

Несмотря на очевидные плюсы от применения математических моделей, подобные нововведения затруднительно осуществлять за короткие сроки. Для создания адекватной модели необходимы статистические данные показателей работы установки за длительный период и учет индивидуальных особенностей объекта (нестабильный состав сырья, износ основных фондов, квалификация обслуживающего персонала).

Известна работа [16], результатом которой стало применение дополнительного форреактора с целью предварительного дегидрирования сырья в более мягких условиях, нежели чем в основном каскаде. Внедрение «дегидрирующего» реактора позволило повысить 
продолжительность работы установки и октановое число получаемого риформата, а также снизить тепловую нагрузку на радиантные камеры печи. Применение форреактора, несомненно, повышает показатели эффективности работы установки, но при этом требует значительных капиталовложений ввиду высокой стоимости платиносодержащего катализатора.

Более универсальным способом повысить технико-экономические показатели процесса является внедрение новых, более совершенных катализаторов. В настоящее время проводится значительное количество исследований в этом направлении [17-19]. Особое внимание уделяется возможности проведения процесса риформинга в присутствии катализатора, не содержащего платину.

Ранее авторами проведены исследования по оценке показателей работы бесплатиновых катализаторов при различных условиях.

По результатам исследований (рисунок 1) сделан вывод о перспективах использования цеолитосодержащего катализатора. Увеличение содержания высокооктановых компонентов (количество аренов возросло на 9,6 \% масс.) и уменьшение содержания н-алканов снизилось на 11,3 \% масс. при практически неизменном количестве нафтенов (содержание снизилось на 1,1 \% масс.) позволяют использовать испытуемый катализатор на этапе подготовки сырья каталитического риформинга. Использование полученного катализата в качестве сырья риформинга позволит получить высокооктановый компонент товарного бензина при меньших затратах на катализатор. 


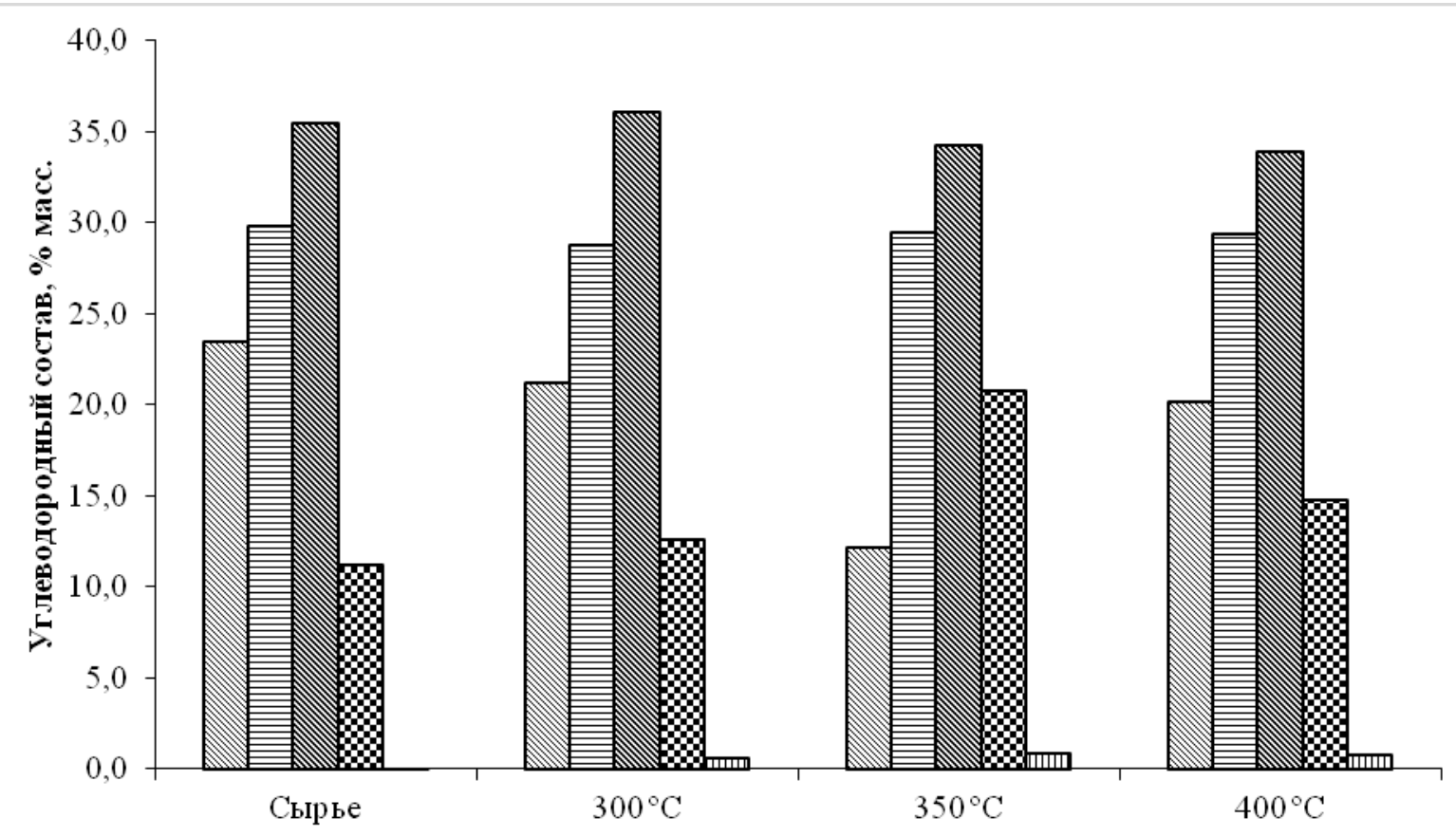

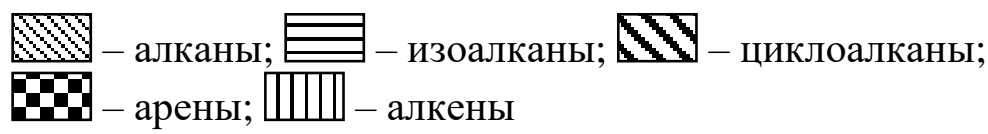

Рисунок 1. Углеводородный состав продуктов

В таблице 1 представлен состав нафтеновых углеводородов, содержащихся в сырье риформинга и в катализате, полученном в результате экспериментов на бесплатиновых катализаторах

Таблица 1. Содержание нафтенов в сырье риформинга и в пробах, полученных при проведении процесса безводородного риформинга при $300{ }^{\circ} \mathrm{C}, 350{ }^{\circ} \mathrm{C}$ и $400{ }^{\circ} \mathrm{C}$

\begin{tabular}{|l|c|c|c|c|}
\hline $\begin{array}{c}\text { Группы } \\
\text { углеводородов }\end{array}$ & $\begin{array}{c}\text { Содержание } \\
\text { нафтенов в сырье } \\
\text { риформинга, } \\
\text { \% об. }\end{array}$ & $\begin{array}{c}\text { Содержание } \\
\text { нафтенов в } \\
\text { пробе } 1\left(300^{\circ} \mathrm{C}\right), \\
\% \text { масс. }\end{array}$ & $\begin{array}{c}\text { Содержание } \\
\text { нафтенов в } \\
\text { пробе 2 }\left(350^{\circ} \mathrm{C}\right), \\
\% \text { масс. }\end{array}$ & $\begin{array}{c}\text { Содержание } \\
\text { нафтенов в } \\
\text { пробе } 3\left(400^{\circ} \mathrm{C}\right), \\
\text { \% масс. }\end{array}$ \\
\hline C6 & 0,47 & 0,56 & 0,48 & 0,35 \\
\hline C7 & 12,36 & 12,94 & 8,80 & 9,97 \\
\hline C8 & 12,32 & 13,93 & 13,76 & 13,27 \\
\hline C9 & 6,20 & 6,54 & 8,14 & 7,27 \\
\hline C10 & 2,38 & 1,94 & 2,71 & 2,52 \\
\hline Общее & 1,71 & 0,24 & 0,45 & 0,51 \\
\hline
\end{tabular}

Установлено, что в составе продуктов, полученных в ходе исследований, содержание нафтенов изменилось незначительно, 
следовательно, реакции дегидрирования нафтенов с получением ароматических на дальнейших стадиях риформинга на платиносодержащих катализаторах будут происходить по классическому механизму.

Снижение содержания н-алканов (таблица 2) влечет за собой уменьшение степени дегидроциклизации, на которые требуется большее количество катализатора и время контакта ввиду низкой скорости протекания реакций.

Таблица 2. Относительная скорость реакций риформинга [20]

\begin{tabular}{|l|c|}
\hline Реакции & Относительная скорость реакций \\
\hline Дегидрогенизация нафтенов & 30 \\
\hline Дегидроциклизация парафинов & 1 (базовая) \\
\hline Изомеризация: парафинов & 3 \\
нафтенов & 3 \\
\hline
\end{tabular}

Поскольку предыдущие эксперименты проводились в безводородном режиме, для дальнейшего изучения показателей работы цеолитосодержащего катализатора в процессе риформинга в настоящем исследовании проведен ряд испытаний в присутствии водорода, но при меньшем давлении, чем в классическом риформинге (0,5 МПа).

В качестве сырья использован прямогонный гидроочищенный бензин фр. $105-180{ }^{\circ} \mathrm{C}$. Процесс проводили в диапазоне температур от $300{ }^{\circ} \mathrm{C}$ до $400{ }^{\circ} \mathrm{C}$. Объемная скорость изменялась от $1 \mathrm{ч}^{-1}$ до $4 \mathrm{ч}^{-1}$ с шагом $1 \mathrm{ч}^{-1}$, соотношение водород : сырье $-750: 1$.

Продолжительность пробега при каждой температуре и объемной скорости составила 8 ч, с отбором проб каждые 4 ч. Общее время работы катализатора составило 100 ч без снижения выхода целевых продуктов.

При температуре $300{ }^{\circ} \mathrm{C}$ (рисунок 2) значительного увеличения содержания ароматических углеводородов в продуктах достигнуть не удалось (максимальный прирост аренов 2,7 \% масс.). Увеличение объемной скорости подачи сырья не оказало существенного влияния на 
выход целевых продуктов (изменение содержания аренов в пробах не превысило 2,5 \% масс.).

При температуре $350 \quad{ }^{\circ} \mathrm{C}$ (рисунок 3) выход ароматических углеводородов изменился незначительно (увеличение содержания аренов составило максимум 4,1 \% масс.). Следует отметить, что при данной температуре увеличилось количество продуктов изомеризации парафиновых углеводородов (снижение содержания парафинов составило от 4,2 \% масс. до 9,2 \% масс., а рост изопарафиновых от 2,5\% масс. до 4,4\% мacc.).

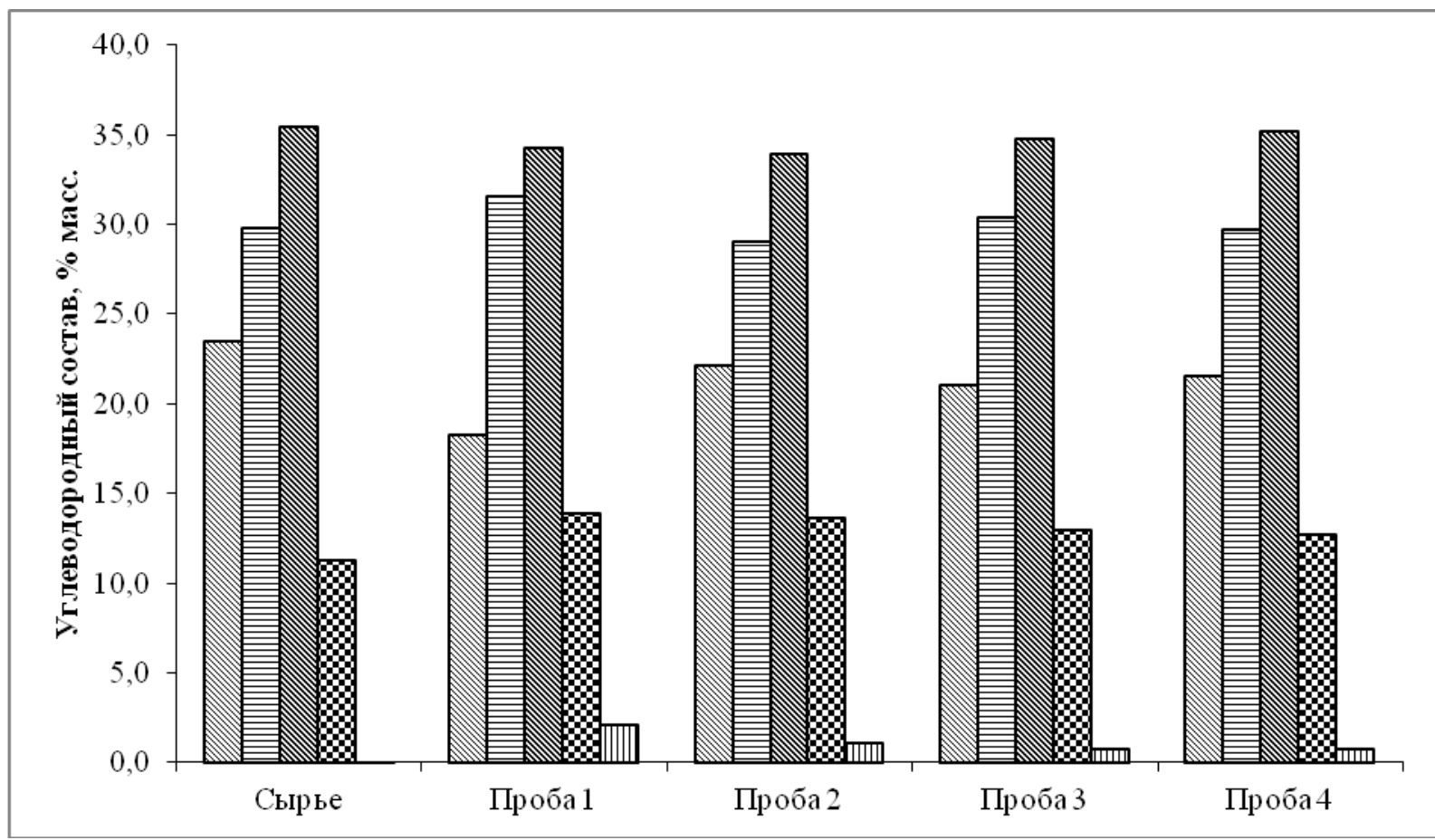

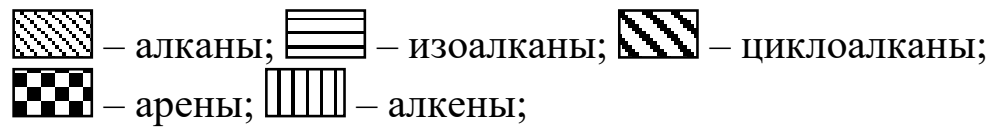

проба 1 - ОСПЧ $=1 ч^{-1}$; проба $2-$ ОСПЧ $=2 ч^{-1}$;

проба 3 - ОСПЧ $=3 ч^{-1}$; проба $4-$ ОСПЧ $=4 ч^{-1}$

Рисунок 2.. Углеводородный состав продуктов, полученных при температуре $300{ }^{\circ} \mathrm{C}$ 


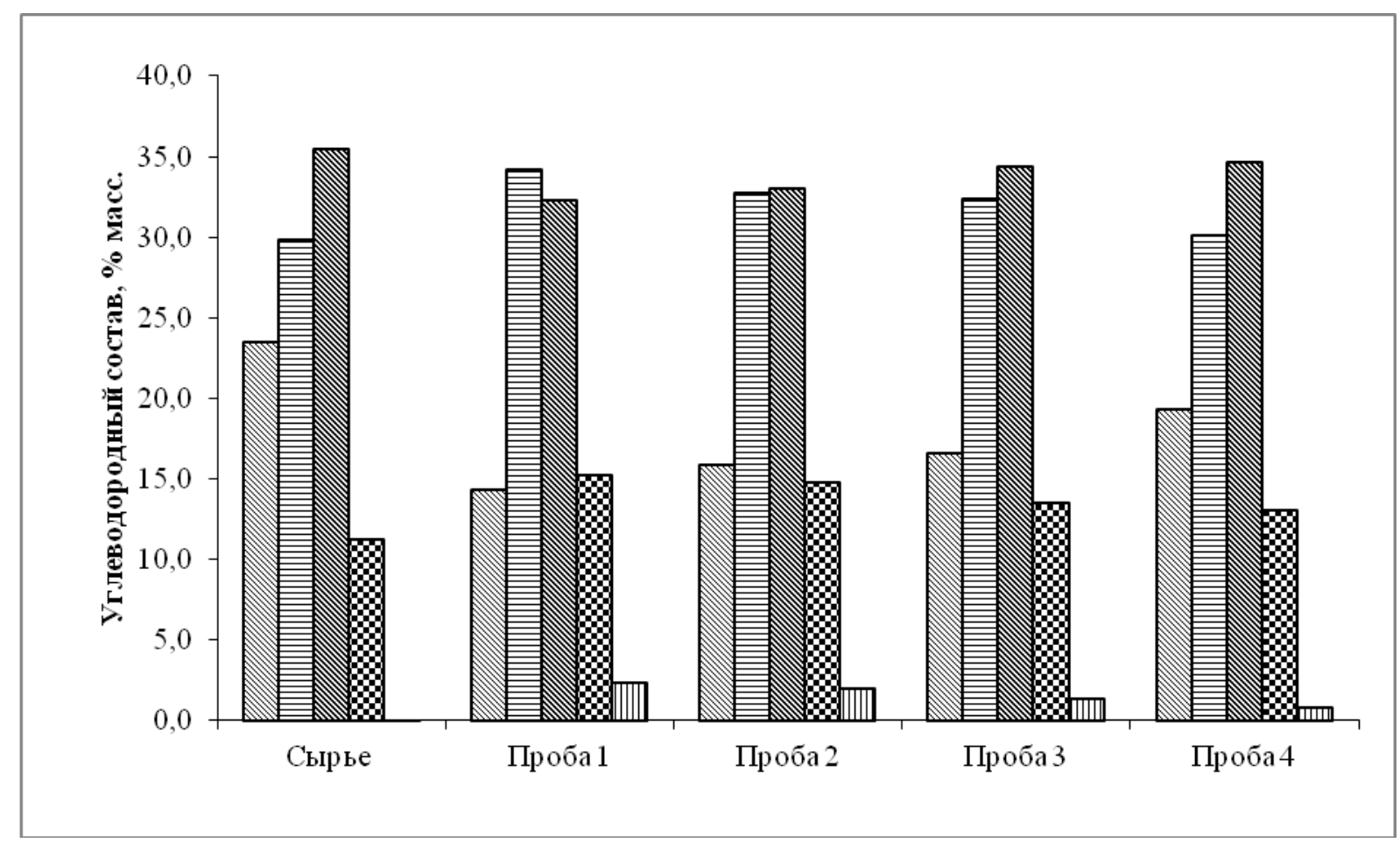

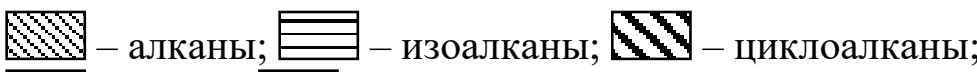

$\mathbf{H}$ - арены; Шा| - алкены;

проба $1-$ ОСПЧ $=1 ч^{-1}$; проба $2-$ ОСПЧ $=2 ч^{-1}$;

проба 3 - ОСПЧ $=3 ч^{-1} ;$ проба $4-$ ОСПЧ $=4 ч^{-1}$

Рисунок 3. Углеводородный состав продуктов, полученных при температуре $350{ }^{\circ} \mathrm{C}$

При температуре $400{ }^{\circ} \mathrm{C}$ (рисунок 4) и объемной скорости 1 ч $^{-1}$ увеличение содержания ароматических углеводородов составило 7,7 \% масс., изопарафинов - 5,8 \% масс., а количество парафинов линейного строения снизилось на $11,3 \%$ масс. С ростом объемной скорости до 2 ч $^{-1}$ выход целевых продуктов уменьшается незначительно (содержание аренов и изопарафинов в продуктовой смеси снизилось на 0,7% масс.). 


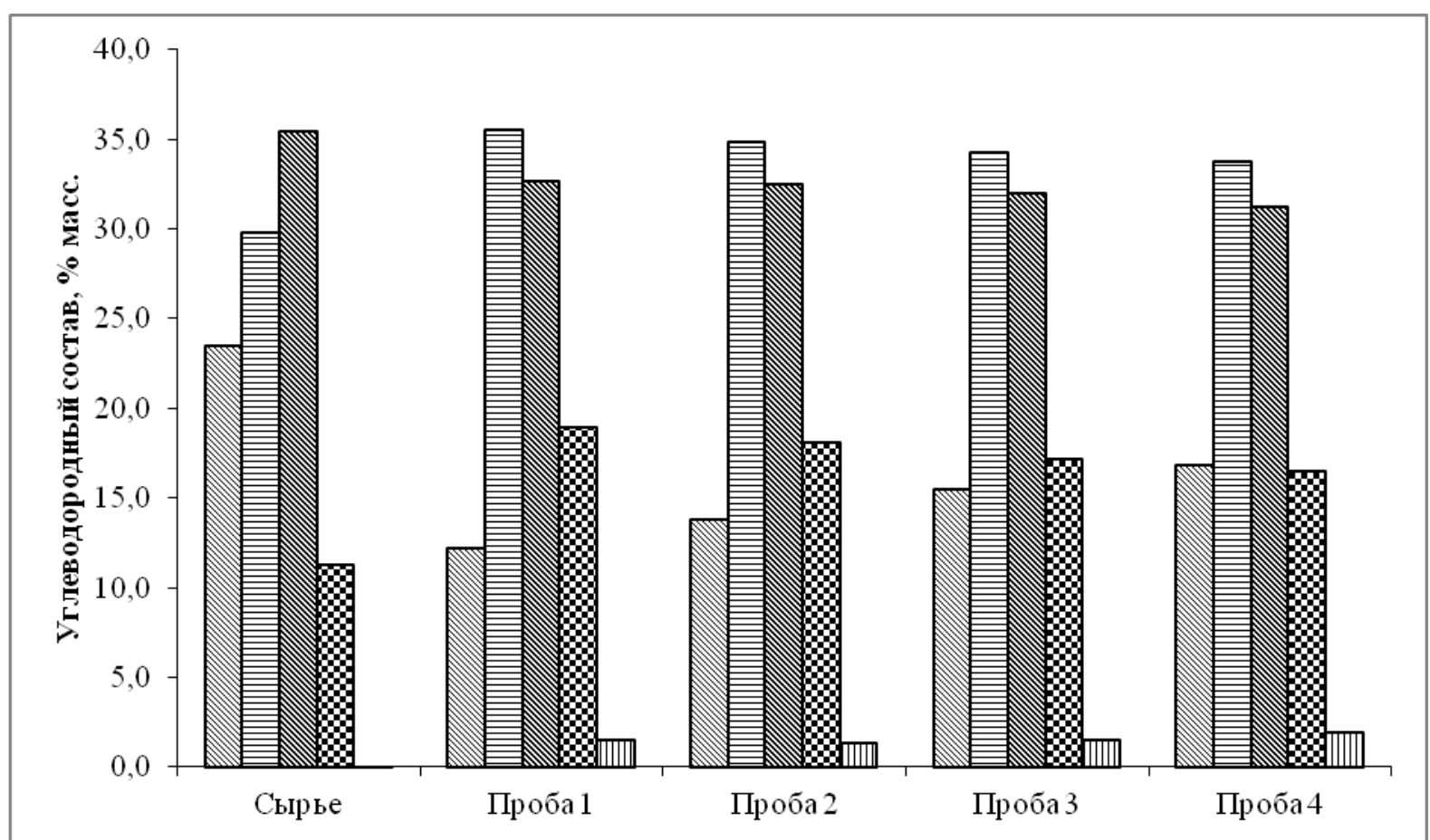

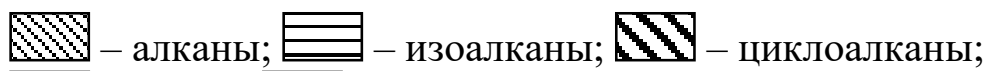

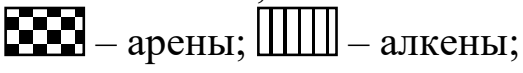

проба 1 - ОСПЧ $=1 ч^{-1}$; проба $2-$ ОСПЧ $=2 ч^{-1}$;

проба 3 - ОСПЧ $=3$ ч $^{-1}$; проба $4-$ ОСПЧ $=4$ ч $^{-1}$

Рисунок 4 - Углеводородный состав продуктов, полученных при температуре $400{ }^{\circ} \mathrm{C}$

\section{Выводы}

Таким образом, результаты исследования показывают возможность применения цеолитосодержащих катализаторов на одной из стадий процесса риформинга бензинов.

Стоит отметить, что исследуемые образцы отличаются универсальностью применения - способны работать как в среде водорода, так и в его отсутствии.

Повышение содержания ареновых углеводородов в полученных продуктах при неизменном количестве нафтеновых позволяет сделать предположение о целесообразности использования исследуемого катализатора на стадии предварительной ароматизации сырья риформинга. 


\section{Список используемых источников}

1. Технический регламент «О требованиях к автомобильному и авиационному бензину, дизельному и судовому топливу, топливу для реактивных двигателей и топочному мазуту». Постановление Правительства Российской Федерации от 27 февраля 2008 г. № 18.

2. Кондрашев Д.О. Повышение выхода и качества риформата за счет совместного применения ступенчатого риформинга и процесса гидроизомеризации // Катализ в промышленности. 2017. № 1. С. 31-36.

3. Ахметов Т.В., Терегулова Э.И., Абдульминев К.Г. Варианты комбинированных технологий каталитического риформинга и изомеризации // Нефтепереработка и нефтехимия. 2012. № 12. С. 27-29.

4. Ясакова Е.А., Ситдикова А.В., Морозов А.Н., Ахметов А.Ф. Разработка вариантов производства высокооктановых бензинов в ОАО «Салаватнефеоргсинтез» // Технологии нефти и газа. 2010. № 2. С. 3-10.

5. Кирьянов Д.И., Смоликов М.Д., Пашков В.В., Проскура А.Г., Затолокина Е.В., Удрас И.Е., Белый А.С. Современное состояние процесса каталитического риформинга бензиновых фракций. Опыт производства и промышленной эксплуатации катализаторов риформинга серии ПР // Российский химический журнал. 2007. № 4. С. 60-69.

6. Плешакова Н.А., Рохманько Е.Н., Салмина И.В., Черепкова Н.Д., Бубнова О.В., Тыщенко В.А., Рудяк К.Б. Опыт эксплуатации отечественных и зарубежных катализаторов риформинга на различных типах сырья // Нефтепереработка и нефтехимия. 2013. № 6. С. 21-25.

7. Крылов В.А., Ходяшев Н.Б., Подвинцев И.Б., Болотова Е.С., Чиркова Н.А. Влияние характера коксовых отложений на показатели работы платино-рениевого катализатора риформинга // Нефтепереработка и нефтехимия. 2013. № 5. С. 14-18. 
8. Гынгазова М.С., Чеканцев Н.В., Короленко М.В., Иванчина Э.Д., Кравцов А.В. Оптимизация кратности циркуляции катализатора в реакторе риформинга с движущимся зернистым слоем сочетанием натурного и вычислительного эксперимента // Катализ в промышленности. 2012. № 2. C. $35-41$.

9. Кравцов А.В., Иванчина Э.Д., Костенко А.В., Шарова Е.С., Фалеев С.А. Анализ эффективности эксплуатации платиносодержащих катализаторов процесса риформинга бензинов с использованием компьютерной моделирующей системы // Нефтепереработка и нефтехимия. 2008. № 11. С. 18-23.

10. Маслянский Г.Н., Шапиро Р.Н. Каталитический риформинг бензинов: Химия и химическая технология. Л.: Химия, 1985. 224 с.

11. Костенко А.В., Молотов К.В., Иванчина Э.Д., Кравцов А.В., Фалеев С.А., Абрамин А.Л. Разработка и применение технологических критериев оценки активности и стабильности Pt-катализаторов риформинга бензинов методом математического моделирования // Нефтепереработка и нефтехимия. 2007. № 6. С. 18-22.

12. Костенко А.В., Молотов К.В., Кравцов А.В., Иванчина Э.Д., Ясюкевич О.М. Мониторинг установки ЛЧ-35-11/1000 с использованием компьютерной системы контроля работы катализаторов риформинга // Нефтепереработка и нефтехимия. 2007. № 4. С. 13-16.

13. Короленко М.В., Гынгазова М.С., Чеканцев Н.В., Иванчина Э.Д., Кравцов А.В. Оптимизация работы блока платформинга установки Л35/11-1000 ОАО «Газмпромнефть-ОНПЗ» с применением расчетов на математической модели процесса // Нефтепереработка и нефтехимия. 2013. № 2. C. 10-15.

14. Иванчина Э.Д., Ивашкина Е.Н., Чеканцев Н.В., Францина Е.В., Шарова E.C. Создание и применение моделирующих систем каталитических нефтехимических процессов в промышленных реакторах // Нефтепереработка и нефтехимия. 2013. № 5. С. 20-26. 
15. Костенко А.В., Кравцов А.В., Иванчина Э.Д., Ивашкина Е.Н. Оптимизация внутренних устройств реакторов риформинга с использованием нестационарной кинетической модели // Нефтепереработка и нефтехимия. 2007. № 1. С. 18-22.

16. Крылов B.А. Совершенствование процессов гидроочистки дизельных топлив и каталитического риформинга бензиновых фракций для переработки вторичных дистиллятов: дисс. ... канд. техн. наук. Пермь, 2007. $160 \mathrm{c}$.

17. Колесников С.И., Кильянов М.Ю., Икорников Д.М., Гущин П.А., Иванов Е.В. Модифицирование катализаторов для процесса каталитического риформинга низкого давления // Нефть, газ и бизнес. 2013. № 1. C. 66-67.

18. Колесников И.М., Винокуров В.А., Кильянов М.Ю., Колесников С.И., Чеховская О.М. Особенности риформинга бензинов на смешанных цеолит Al-Сo-Мо-О катализаторах // Нефть, газ и бизнес. 2010. № 5. C. 79-84.

19. Кузьмина Р.И., Фролов М.П., Ливенцев В.Т., Ветрова Т.К., Ковнев А.В. Разработка цеолитсодержащего катализатора риформинга // Катализ в промышленности. 2010. № 6. С. 29-34.

\section{References}

1. Tehnicheskii reglament $« \mathrm{O}$ trebovaniyah $\mathrm{k}$ avtomobil'nomu $\mathrm{i}$ aviatsionnomu benzinu, dizel'nomu i sudovomu toplivu, toplivu dlya reaktivnyh dvigatelei i topochnomu mazutu». Postanovlenie Pravitel'stva Rossiyiskoi Federatsii ot 27 fevralya 2008 g. № 18 [Technical Regulations «About Requirements To Automobile and Aviation Gasoline, Diesel And Marine Fuel, Fuel for Reactive Engines and Heating Oil». Decree of the Government of Russian Federation of February 27, 2008. No. 18. [in Russian]. 
2. Kondrashev D.O. Povyshenie vyhoda i kachestva riformata za schet sovmestnogo primeneniya stupenchatogo riforminga i processa gidroizomerrizatsii [Increase of the Yield and the Quality of Reformate due to the Combined Use of Stepwise Reforming and The Hydroisomerization Process]. Kataliz v promyshlennosti - Catalysis in Industry, 2017, No. 1, pp. 31-36. [in Russian].

3. Akhmetov T.V., Teregulova E.I., Abdulminev K.G. Varianty kombinirovannyh tehnologii kataliticheskogo riforminga $\mathrm{i}$ isomerizatsii [Variants of Combined Technologies of Catalytic Reforming and Isomerization]. Neftepererabotka i neftehimiya - Oil Refining and Oil Chemistry, 2012, No. 12, pp. 27-29. [in Russian].

4. Yasakova E.A., Sitdikova A.V., Morozov A.N., Akhmetov A.F. Razrabotka variantov proizvodstva vysokooktanovyh benzinov v OAO «Salavatnefteorgsintez» [Development of Options of the Production of HighOctane Gasoline at JSC «Salavatnefteorgsintez»]. Tehnologii nefti i gaza - Oil and Gas Technologies, 2010, No. 2, pp. 3-10. [in Russian].

5. Kiryanov D.I., Smolikov M.D., Pashkov V.V., Proskura A.G., Zatolokina E.V., Udras I.E., Belyi A.S. Sovremennoe sostoyanie protsessa kataliticheskogo riforminga benzinovykh fraktsii. Opyt proizvodstva i promyshlennoi ekspluatacii katalizatorov riforminga serii PR [The Current State of the Process of Catalytic Reforming of Gasoline Fractions. Experience in the Production and Industrial Operation of Reforming Catalysts of the PR Series]. Rossiiskii himicheskii zhurnal - Russian Chemical Journal, 2007, No. 4, pp. 60-69. [in Russian].

6. Pleshakova N.A., Rohman'ko E.N., Sakmina I.V., Cherepkova N.D., Bubnova O.V., Tysh'enko V.A., Rudyak K.B. Opyt ekspluatatsii otechestvennyh i zarubezhnyh katalizatorov riforminga na razlichneyh tipah syr'iya [Experience in Operating Domestic and Foreign Reforming Catalysts on Various types of Raw Materials]. Neftepererabotka I neftehimiya - Oil Refining and Oil Chemistry, 2013, № 6, pp. 21-25. [in Russian]. 
7. Krylov V.A., Hodyash'ev N.B., Podvintsev I.B., Bolotova E.S., Chirkova N.A. Vliyaniye haraktera koksovyh otlozhenii na pokazateli raboty platino-renievogo katalizatora riforminga [Effect of the Nature of Coke Deposits on the Performance of the Platinum-Rhenium Reforming Catalyst]. Neftepererabotka i neftehimiya - Oil Refining and Oil Chemistry, 2013, No. 5, pp. 14-18. [in Russian].

8. Gyngazova M.S., Chekantsev N.V., Korolenko M.V., Ivanchina E.D., Kravtsov A.V. Optimizatsiya kratnosti tsirkuliyatsii katalizatora $\mathrm{v}$ reaktore riforminga $\mathrm{s}$ dvizhush'imsiya zernistym sloem sochetaniem naturnogo $\mathrm{i}$ vychislitel'nogo eksperimenta [Optimization of the Circulation Rate of the Catalyst in a Reforming Reactor with a Moving Granular Layer by Combining the Full-Scale and Computational Experiment]. Kataliz v proyshlennosti Catalysis in Industry, 2012, No. 2, pp. 35-41. [in Russian].

9. Kravtsov A.V., Ivanchina E.D., Kostenko A.V., Sharova E.S., Faleev S.A. Analiz effektivnosti ekspluatacii platinosoderzhash'ih katalizatorov protsessa riforminga benzinov s ispol'zovaniem komp'yuternoi modeliruyush'ei sistemy [Analysis of the Effectiveness of the Operation of Platinum-Containing Catalysts for the Gasoline Process Using a Computer Simulation System]. Neftepererabotka i neftehimiya - Oil Refining and Oil Chemistry, 2008, No. 11, pp. 18-23. [in Russian].

10. Maslyanskii G.N., Shapiro R.N. Kataliticheskii reforming benzinov: Himiya i himicheskaiya tehnologiya [Catalytic Reforming of Gasolines: Chemistry and Chemical Technology]. Leningrad, Himiya Publ., 1985. 224 p. [in Russian]. 
11. Kostenko A.V., Molotov K.V., Kravtsov A.V., Ivanchina E.D., Faleev S.A., Abramin A.L. Razrabotka i primenenie tehnologicheskih kriteriev otsenki aktivnosti i stabil'nosti Pt-katalizatorov riforminga benzinov metodom matematicheskogo modelirovaniya [Development and Using of Technological Criteria for Assessing the Activity and Stability of Pt-Catalysts for Gasoline Reforming by Mathematical Modelling]. Neftepererabotka i neftehimiya - Oil Refining and Oil Chemistry, 2007, No. 6, pp.18-22. [in Russian].

12. Kostenko A.V., Molotov K.V., Kravtsov A.V., Ivanchina E.D., Yasyukevich O.M. Monitoring ustanovki LCH-35-11/1000 s ispol'zovaniem komp'yuternoi modeli sistemy kontroliya raboty katalizatorov riforminga [Monitoring of the LCH-35-11/1000 Installation Using Computerized Monitoring System for the Operation of Reforming Catalysts]. Neftepererabotka i neftehimiya - Oil Refining and Oil Chemistry, 2007, No. 4, pp. 13-16. [in Russian].

13. Korolenko M.V., Gyngazova M.S., Chekantsev N.V., Ivanchina E.D., Kravtsov A.V. Optimizatsiya raboty bloka platforminga ustanovki L-35/11-1000 OAO «Gazpromneft'-ONPZ»s primeneniem raschetov na matematicheskoi modeli protsessa [Optimization of the Operation of The Platforming Unit L35/11-1000 Unit of JSC «Gazpromneft-ONPZ» Using Calculation on Mathematical Model of the Process]. Neftepererabotka i neftehimiya - Oil Refining and Oil Chemistry, 2013, No. 2, pp. 10-15. [in Russian].

14. Ivanchina E.D., Ivashkina E.N., Chekantsev N.V., Frantsina E.V., Sharova E.S. Sozdanie i primenenie modeliruiyush'ih system kataliticheskih neftehimicheskih protsessov $\mathrm{v}$ promyshlennyh reaktorah [Creation and Using of Modelling Systems of Catalytic Petrochemical Processes in Industrial Reactors]. Neftepererabotka i neftehimiya - Oil Refining and Oil Chemistry, 2013, No. 5, pp. 20-26. [in Russian]. 
15. Kostenko A.V., Kravtsov A.V., Ivanchina E.D., Ivashkina E.N. Optimizatsiya vnutrennih ustroistv reaktorov riforminga $\mathrm{s}$ ispol'zovaniem nestatsionarnoi kineticheskoi modeli [Optimization of Internal Arrangements of Reforming Reactors Using a Non-Stationary Kinetic Model]. Neftepererabotka i neftehimiya - Oil Refining and Oil Chemistry, 2007, No. 1, pp. 18-22. [in Russian].

16. Krylov V.A. Sovershenstvovanie protsessov gidroochistki dizel'nyh topliv i kataliticheskogo riforminga benzinovyh fraktsii dlya pererabotki vtorichnyh distillyatov: dis. kand. tekhn. nauk [Improvement of Hydrotreating of Diesel Fuels and Catalytic Reforming of Gasoline Fractions for Refining of Secondary Distillates: Cand. Tekhn. Sci. Diss.]. Perm, 2007, 22 p. [in Russian].

17. Kolesnikov S.I., Kil'yanov M.Yu., Ikornikov D.M., Gush'in P.A., Ivanov E.V. Modifitsirovanie katalizatorov dlya protsessa kataliticheskogo riforminga nizkogog davleniya [Modification of Catalysts for Low Pressure Catakytic Reforming Process]. Neft', gaz i biznes - Oil, Gas and Business, 2013, No. 1, pp. 66-67. [in Russian].

18. Kolesnikov I.M., Vinokurov V.A., Kil'yanov M.Yu., Kolesnikov S.I., Chehovskaiya O.M. Osobennosti riforminga benzinov na smeshannyh tseolit AlCo-Mo-O katalizatorah [Features of Gasoline Reforming On Mixed Zeolite AlCo-Mo-O Catalysts]. Neft', gaz i biznes - Oil, Gas and Business, 2010, No. 5, pp. 79-84. [in Russian].

19. Kuz'mina R.I., Frolov M.P., Liventsev V.T., Vetrova T.K., Kovnev A.V. Razrabotka tseolitsodersh'ego katalizatora riforminga [Reforming ZeolitContaining Catalyst Development]. Kataliz v promyshlennosti - Catalysis in Industry, 2010, No. 6, pp. 29-34. [in Russian]. 


\section{Сведения об авторах}

\section{About the authors}

Муниров Т.А., аспирант кафедры «Технология нефти и газа», ФГБОУ ВО «УГНТУ», г. Уфа, Российская Федерация

T.A. Munirov, Post-Graduate Student of Oil and Gas Technology Department, FSBEI HE «USPTU», Ufa, Russian Federation

e-mail: timur_zuleika-91@mail.ru

Давлетшин А.Р., канд. техн. наук, доцент кафедры «Технология нефти и газа», ФГБОУ ВО «УГНТУ», г. Уфа, Российская Федерация

A.R. Davletshin, Candidate of Technical Sciences, Assistant Professor of Oil and Gas Technology Department, FSBEI HE «USPTU», Ufa, Russian Federation

e-mail: fueldep@inhp.ru

Шириязданов Р.Р., канд. техн. наук, доцент кафедры «Газохимия и моделирование химико-технологических процессов», ФГБОУ $\mathrm{BO}$ «УГНТУ», г. Уфа, Российская Федерация

R.R. Shiriyazdanov, Candidate of Technical Sciences, Assistant Professor of Gas Chemistry and Modelling of Chemical-Technological Processes Department, FSBEI HE «USPTU», Ufa, Russian Federation

e-mail: petroleum9@bk.ru

Ахметов А.Ф., д-р техн. наук, профессор кафедры «Технология нефти и газа», ФГБОУ ВО «УГНТУ», г. Уфа, Российская Федерация

A.F. Akhmetov, Doctor of Technical Sciences, Professor of Oil and Gas Technology Department, FSBEI HE «USPTU», Ufa, Russian Federation e-mail: tngrusoil@mail.ru 
Хамзин Юнир Азаматович, аспирант кафедры «Технология нефти и газа», ФГБОУ ВО «УГНТУ», г. Уфа, Российская Федерация

Yu.A. Khamzin, post-graduate student of Oil and Gas Technology Department, FSBEI HE «USPTU», Ufa, Russian Federation

e-mail: yunirkh@bk.ru

Ганцев А.В., канд. техн. наук, доцент кафедры «Технология нефти и газа», ФГБОУ ВО «УГНТУ», г. Уфа, Российская Федерация

A.V. Gantsev, Candidate of Technical Sciences, Assistant Professor of Oil and Gas Technology Department, FSBEI HE «USPTU», Ufa, Russian Federation

e-mail: a.v.ganzev@yandex.ru

Амангельдиев Д.М., магистрант кафедры «Технология нефти и газа», ФГБОУ ВО «УГНТУ», г. Уфа, Российская Федерация

D.M. Amangeldiyev, Undergraduate Student of Oil and Gas Technology Department, FSBEI HE «USPTU», Ufa, Russian Federation

e-mail:daua95@mail.ru 